\title{
Odontogenic keratocyst: imaging features of a benign lesion with an aggressive behaviour
}

\author{
Andrea Borghesi ${ }^{1,2} \cdot$ Cosimo Nardi $^{3,4} \cdot$ Caterina Giannitto $^{5} \cdot$ Andrea Tironi $^{6} \cdot$ Roberto Maroldi $^{1,2}$. \\ Francesco Di Bartolomeo ${ }^{7} \cdot$ Lorenzo Preda $^{8,9}$
}

Received: 13 April 2018 /Revised: 7 June 2018 / Accepted: 28 June 2018 /Published online: 31 July 2018

(C) The Author(s) 2018

\begin{abstract}
The latest (4th) edition of the World Health Organization (WHO) Classification of Head and Neck Tumours, published in January 2017, has reclassified keratocystic odontogenic tumour as odontogenic keratocyst. Therefore, odontogenic peak of incidence in the third decade of life and a slight male predominance. OKCs originate in tooth-bearing regions and the mandible is more often affected than the maxilla. In the mandible, the most common location is the posterior sextant, the angle or the ramus. Conversely, the anterior sextant and the third molar region are the most common sites of origin in the maxilla. OKCs are characterised by an aggressive behaviour with a relatively high recurrence rate, particularly when OKCs are associated with syndromes. Multiple OKCs are typically associated with the nevoid basal cell carcinoma syndrome in selected cases, magnetic resonance imaging (MRI), plays an important role in the diagnosis and management of OKCs. Therefore, the main purpose of this pictorial review is to present the imaging appearance of OKCs underlining the specific findings of different imaging modalities and to provide key radiologic features helping the differential diagnoses from other cystic and neoplastic lesions of odontogenic origin.

\section{Key Points}

- Panoramic radiography is helpful in the preliminary assessment of OKCs.

- $C T$ is considered the tool of choice in the evaluation of OKCs.

- MRI with DWI or DKI can help differentiate OKCs from other odontogenic lesions.

- Ameloblastoma, dentigerous and radicular cysts should be considered in the differential diagnosis.

- The presence of multiple OKCs is one of the major criteria for the diagnosis of NBCCS.
\end{abstract} keratocysts (OKCs) are now considered benign cysts of odontogenic origin that account for about $10 \%$ of all odontogenic cysts. OKCs arise from the dental lamina and are characterised by a cystic space containing desquamated keratin with a uniform lining of parakeratinised squamous epithelium. The reported age distribution of OKCs is considerably wide, with a (NBCCS), an autosomal dominant multisystemic disease. Radiological imaging, mainly computed tomography (CT) and,

Keywords Odontogenic keratocysts · Panoramic radiography · Computed tomography · Magnetic resonance imaging · Basal cell nevus syndrome

Lorenzo Preda

lorenzo.preda@unipv.it

1 Department of Radiology, University of Brescia, Brescia, Italy

2 Spedali Civili di Brescia, Brescia, Italy

3 Department of Experimental and Clinical Biomedical Sciences, Radiodiagnostic Unit Number 2, University of Florence, Florence, Italy

4 Azienda Ospedaliera Universitaria Careggi, Florence, Italy
5 Division of Radiology, European Institute of Oncology, Milan, Italy

6 Department of Pathology, Spedali Civili di Brescia, Brescia, Italy

7 Postgraduate School in Radiodiagnostics, Università degli Studi di Milano, Milan, Italy

8 Department of Clinical-Surgical, Diagnostic and Pediatric Sciences, University of Pavia, Pavia, Italy

9 Diagnostic Imaging Unit, National Centre of Oncological Hadrontherapy (CNAO), Pavia, Italy 


$\begin{array}{ll}\text { Abbreviations } \\ \text { ADC } & \text { Apparent diffusion coefficient } \\ \text { CBCT } & \text { Cone beam computed tomography } \\ \text { CT } & \text { Computed tomography } \\ \text { DKI } & \text { Diffusion kurtosis imaging } \\ \text { DWI } & \text { Diffusion-weighted imaging } \\ \text { KCOT } & \text { Keratocystic odontogenic tumour } \\ \text { MDCT } & \text { Multidetector computed tomography } \\ \text { MPR } & \text { Multiplanar reconstruction } \\ \text { MRI } & \text { Magnetic resonance imaging } \\ \text { NBCCS } & \text { Nevoid basal cell carcinoma syndrome } \\ \text { OKC } & \text { Odontogenic keratocyst } \\ \text { PTCH } & \text { Protein patched homolog } \\ \text { WHO } & \text { World Health Organization }\end{array}$

\section{Introduction}

Odontogenic keratocysts (OKCs), first described by Philipsen in 1956 [1], are benign intraosseous lesions of odontogenic origin that account for about $10 \%$ of jaw cysts. They are characterised by an aggressive behaviour with a relatively high recurrence rate [2]. Histologically, OKCs arise from the dental lamina and are constituted by a cystic space containing desquamated keratin, lined with a uniform parakeratinised squamous epithelium of 5 to 10 cell layers, with a distinct basal layer of palisaded columnar or cuboidal cells, whose nuclei tend to be vertically oriented. The interface with the adjacent connective tissue is normally flat with a potential for budding of the basal layer and the formation of small satellite cysts [3]. The mitotic activity is higher than other cysts of odontogenic origin [4].

Because of this histologic feature, the aggressive behaviour and the fact that a large proportion of lesions are associated with a mutation or inactivation of the tumour suppressor gene, also called the protein patched homolog (PTCH) gene, in the 3rd edition of the World Health Organization (WHO) Classification of Head and Neck Tumours, this pathological entity was included in the group of odontogenic neoplasms with the name of keratocystic odontogenic tumour (KCOT) [5].

In the latest (4th) edition of the WHO Classification of Head and Neck Tumours published in January 2017 [6], the consensus group concluded that, at the present time, there is insufficient evidence to support a neoplastic origin of this cystic lesion and that further research is needed [7]. Consequently, the name $\mathrm{OKC}$ has been reinserted, replacing the term KCOT that was removed from the classification.

Preoperative assessment is important for planning treatment and management, as OKCs require a more aggressive treatment than other low-attenuating lesions having similar radiological appearance.

The aim of this pictorial review is to present the imaging appearance of OKCs underlining the specific findings of different imaging modalities and to provide key radiologic features helping the differential diagnoses from other cystic and neoplastic lesions of odontogenic origin.

\section{Incidence, clinical presentation and natural history}

OKCs represent approximately $10 \%$ of odontogenic cysts and the reported age distribution is considerably wide (from 8 to 82 years), with a peak of incidence in the third decade of life $[3,8,9]$. Most series have shown a slight preponderance in males [10].

The presence of multiple OKCs, also occurring in different moments during the lifetime of the patients, is typically associated with the nevoid basal cell carcinoma syndrome (NBCCS), also known as Gorlin-Goltz syndrome, an autosomal dominant multisystemic disease. In these patients, the mean age of incidence decreases to about 25 years old [11-13].

Similarly to other entities having an odontogenic origin, OKCs originate in tooth-bearing regions. They occur twice as often in the mandible as in the maxilla [14]. When OKCs originate from the mandible, the most common location is the posterior sextant, the angle or the ramus $[15,16]$. Conversely, the anterior sextant, mainly between canine and lateral incisor, and the third molar region are the most common sites of origin in the maxilla $[17,18]$. Large size lesions are particularly common at the angle and ramus of the mandible [19]. According to the literature, OKCs may be located in a periapical position, in a pericoronal position or in a lateral root position. In about $30 \%$ of cases, they have no relationships with any dental structures $[10$, 17]. In spite of their aggressive behaviour, OKCs, in most cases, cause minimal bone expansion because of their propensity to spread along the intramedullary space "growing in the length of the bone" [20]. Large lesions, causing significant erosion of cortical plates and involvement of surrounding structures, may be seen in asymptomatic patients [21]. Consequently, especially in western countries, the presence of OKCs may be found at a later stage as an incidental finding during routine radiological investigations. A systematic review of the literature published in 2011 by MacDonald-Jankowski showed that patients of East Asian origin may present symptoms early, characterised by swelling and pain, while discharge and numbness of the inferior alveolar nerve are described more frequently in Latin Americans [22]. Unlike other odontogenic lesions having similar aggressive behaviour such as ameloblastomas, OKCs infrequently cause root resorption of adjacent teeth [10].

The reported recurrent rate of OKCs after surgery is wide, up to $30 \%$, with most recurrences occurring after conservative treatments of simple lesion's enucleation [2, 19, 23].

Higher recurrence rates are reported in patients affected by NBCCS and in multilocular lesions [24, 25]. The recurrences might be explained by different causes: incomplete removal of highly active basal layer of the epithelial cyst lining, growth of 
small intramedullary satellite cysts left behind by conservative treatment and development of lesions localised in the adjacent region of the jaws $[13,19,26]$. The type of surgery may not be the only factor and some authors suggested that recurrence may be related with the biological nature of the lesion itself and the expression of proliferative markers such as Ki-67 [27, 28].

\section{Imaging techniques}

The radiological imaging techniques most commonly used in the study of OKCs are conventional radiography (mainly panoramic radiography), computed tomography (CT) and magnetic resonance imaging (MRI). These imaging modalities differ significantly in their technical characteristics, acquisition modalities, indications and information provided.

\section{Panoramic radiography}

Panoramic radiography is a flat representation of the curved surfaces of the maxillary and mandibular dental arches and is helpful in the preliminary assessment of the location, size, shape, margins and extension of odontogenic lesions, such as OKCs. However, this radiographic technique has a limited role because it provides a two-dimensional view of maxillofacial structures with magnification, geometric distortion and overlapping. Therefore, to overcome the limitations of panoramic radiography, a three-dimensional imaging modality is often required for preoperative planning, particularly in larger lesions.

Radiographically, OKCs appear as a well-defined unilocular or multilocular radiolucency bounded by corticated margins (Fig. 1). Unilocular lesions are predominant, whereas the multilocular variant is observed in approximately $30 \%$ of cases, most commonly in the mandible (Fig. 1b) $[9,29]$. On panoramic radiography, mandibular unilocular OKCs may show few and incomplete septa within the lesions; this finding is more common in larger than in smaller OKCs (Fig. 2).

Approximately $30 \%$ of OKCs are associated with at least one unerupted tooth, most commonly the third molars (Fig. 1a) $[9,29]$. This association occurs particularly in younger patients [15].

The radiographic features of OKCs are not pathognomonic, particularly in smaller unilocular lesions [15]. When a small unilocular OKC occurs in the anterior sextant of the maxilla, it may simulate other odontogenic and non-odontogenic cysts, such as radicular cyst (Fig. 3), lateral periodontal cyst or nasopalatine cyst $[17,30]$.

Large mandibular OKCs tend to grow predominantly along the length of the bone with minimal bucco-lingual expansion, especially within the body [15]. On panoramic radiography, this peculiar pattern of growth may determine an extensive radiolucent lesion with considerable mesiodistal dimensions

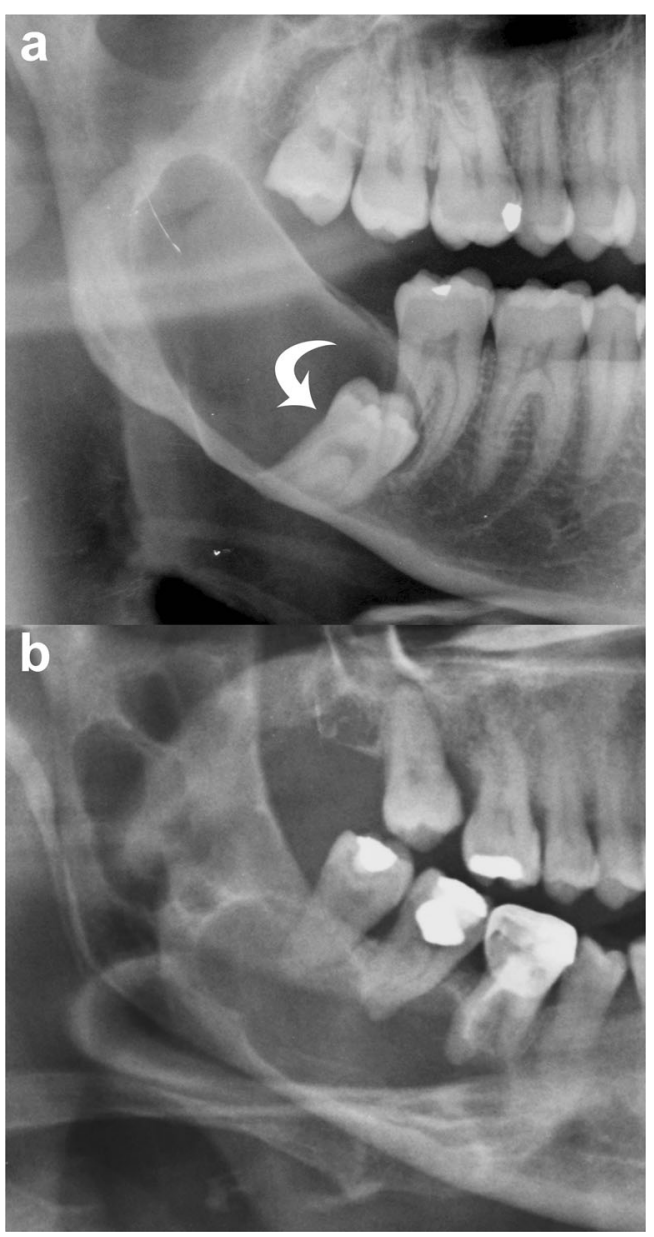

Fig. 1 Mandibular odontogenic keratocysts (OKCs). a Cropped panoramic radiograph shows a unilocular lesion in the posterior mandible and ramus that determines mesial displacement of the impacted third molar (curved arrow). b Cropped panoramic radiograph demonstrates a multilocular lesion occupying the posterior mandible and ramus with a soap-bubble pattern

and without a significant cortical expansion (Figs. 1a and 2). On the other hand, large maxillary OKCs display a significant expansion of the alveolar bone and tend to involve adjacent

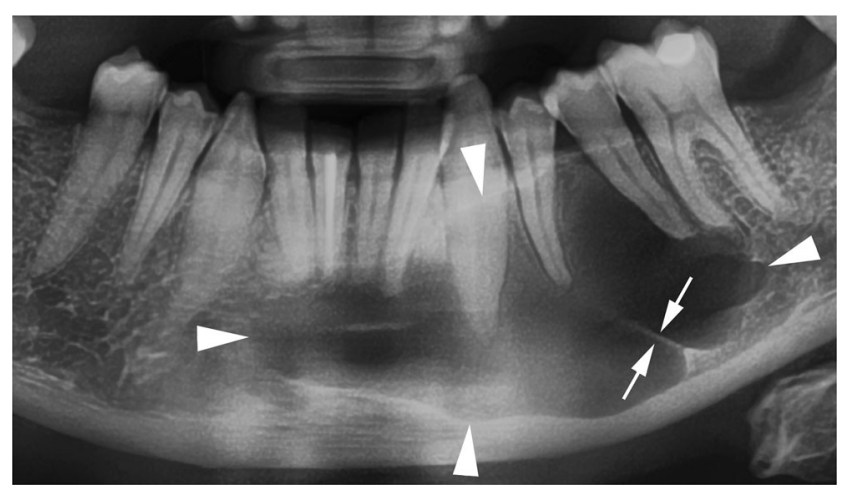

Fig. 2 Cropped panoramic radiograph shows a large OKC with welldefined and lobulated margins (arrowheads) occupying the body of the mandible. Note an incomplete internal septum within the lesion (opposing arrows) 


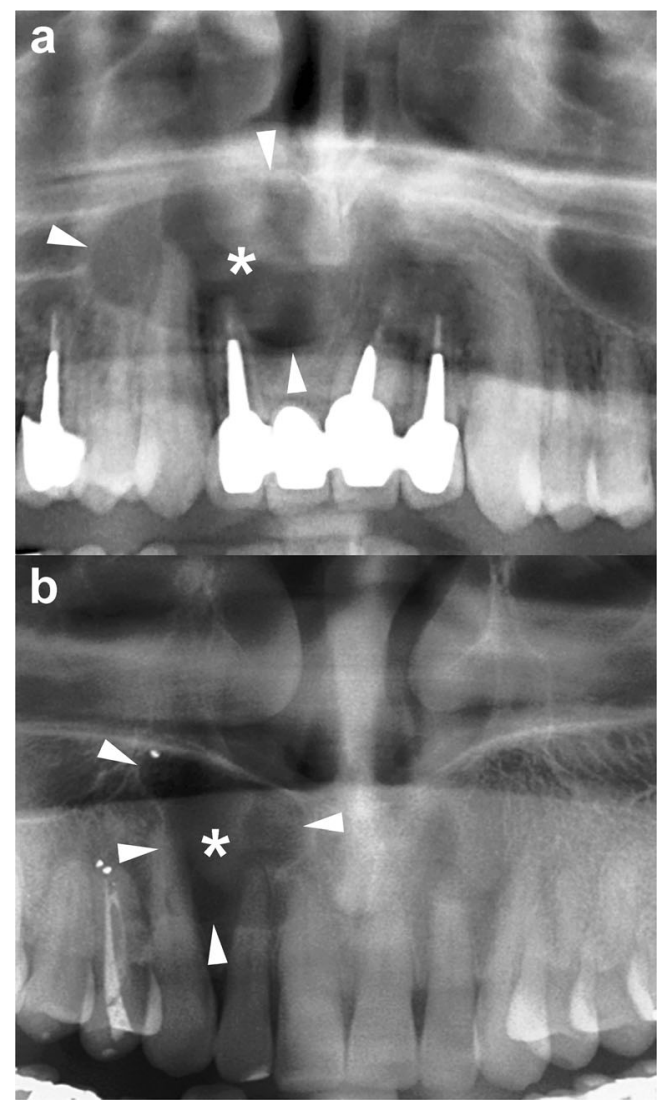

Fig. 3 Histologically proven OKCs. Cropped panoramic radiographs (a and b) show two unilocular radiolucent lesions (asterisks) with welldefined and corticated margins (arrowheads) located in the anterior maxilla, between the roots of the adjacent teeth. The radiographic aspect of these radiolucent lesions may simulate a radicular cyst

structures. In particular, when a maxillary OKC originate from the molar region, an extension into the maxillary sinus is frequently seen (Fig. 4) [22].

Radiographically, OKCs may show tooth displacement and root resorption; this latter finding is an uncommon radiographic feature of OKCs, with a reported incidence varying from 1.3 to $11 \%$ [9]. The literature reported that the perforation of the cortical bone is not an unusual feature of OKCs, with an intraoperative incidence varying from 39 to 51\% [9]. However this finding is detected very rarely on panoramic radiography and is generally limited to the alveolar crest.

\section{Cone beam and multidetector computed tomography}

In clinical routine, there are two main $\mathrm{CT}$ techniques commonly used for the evaluation of maxillofacial diseases: cone beam CT (CBCT) and multidetector CT (MDCT). Both CT modalities are usually considered adequate for diagnosing OKCs and preoperative planning, owing to their ability to generate high-quality multiplanar reconstruction (MPR) images in different planes. In addition, using a dedicated reconstruction software for dental arches (DentaScan), the three-

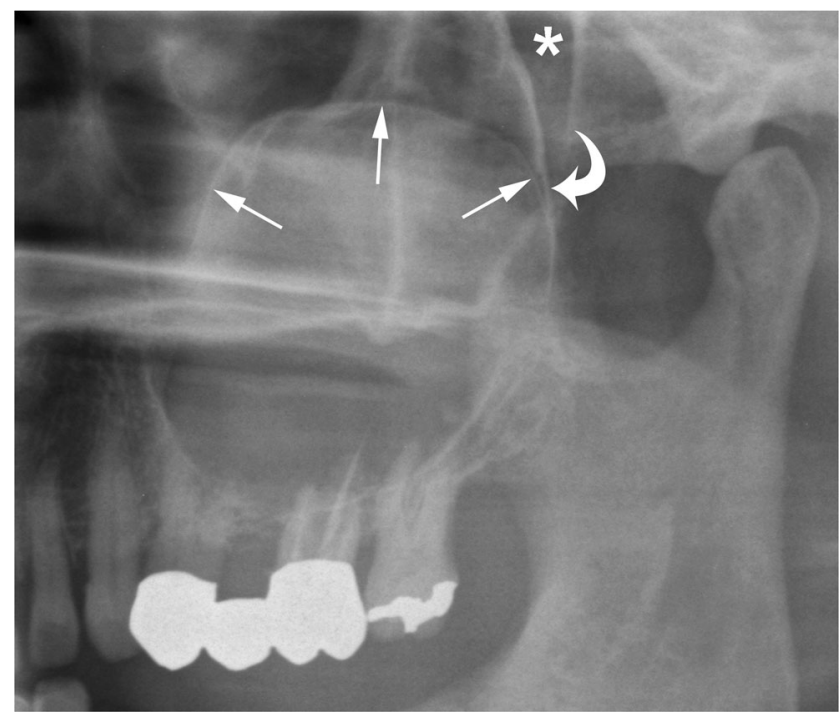

Fig. 4 Cropped panoramic radiograph of the posterior left maxilla demonstrates a large OKC extending into the maxillary sinus (arrows). The posterior wall of the maxillary sinus (curved arrow) and the pterygopalatine fossa (asterisk) are also displayed

dimensional dataset produced by both modalities can be further processed in MPR images that are either parallel (panoramic) or perpendicular (cross-sectional) to the curvature of the alveolar bones. These high-resolution MPR images allow three-dimensional views of the jaws and provide detailed information about the $\mathrm{OKC}$ and its relationship with surrounding structures (teeth, sinonasal cavities, canals, foramina and soft tissue).

The main advantage that makes $\mathrm{CBCT}$ a particularly attractive technique in the evaluation of maxillary and mandibular lesions is its higher spatial resolution compared with MDCT. Conversely, the main disadvantage of CBCT is the poor contrast resolution, which is not suitable for soft tissue contrast discrimination. Hence, CBCT is not able to evaluate the extension into soft tissues and precludes the possibility of contrast medium injection [31]. In the assessment of an OKC, $\mathrm{CBCT}$ is considered more effective to demonstrate the bony changes of the cortical plates of jaws (buccal, palatal or lingual cortices), whereas MDCT is more effective at evaluating internal density and extension into soft tissue.

As with panoramic radiography, $\mathrm{CT}$ is able to display the main radiological features of an $\mathrm{OKC}$, such as size, shape (hydraulic or scalloping), margins (well-defined and corticated), internal appearance (uni- or multilocular) and effects on adjacent structures (tooth displacement, root resorption, maxillary sinus floor elevation, inferior displacement of mandibular canal) [32]. In addition, CT demonstrates other features of OKCs, such as bony changes (expansion in buccolingual/palatal direction and erosion), internal density and extension into soft tissue (Fig. 5).

Therefore, CT is considered superior to conventional radiography in differentiating OKCs from other unilocular or 
Fig. 5 Maxillary OKC. Panoramic radiograph (a) shows a large radiolucency with a welldefined and corticated rim in the maxilla (white arrows). Axial multidetector computed tomography (MDCT) images with bone window (b) and soft tissue window (c) clearly demonstrate the hydraulic expansion of the maxillary alveolar bone (black arrows) with thinning (wavy arrows) and perforation (curved arrows) of the buccal cortex. Posterior bowing of the floor of the maxillary sinuses (arrowheads) and inflammatory material within the left maxillary sinus (asterisks) are also shown

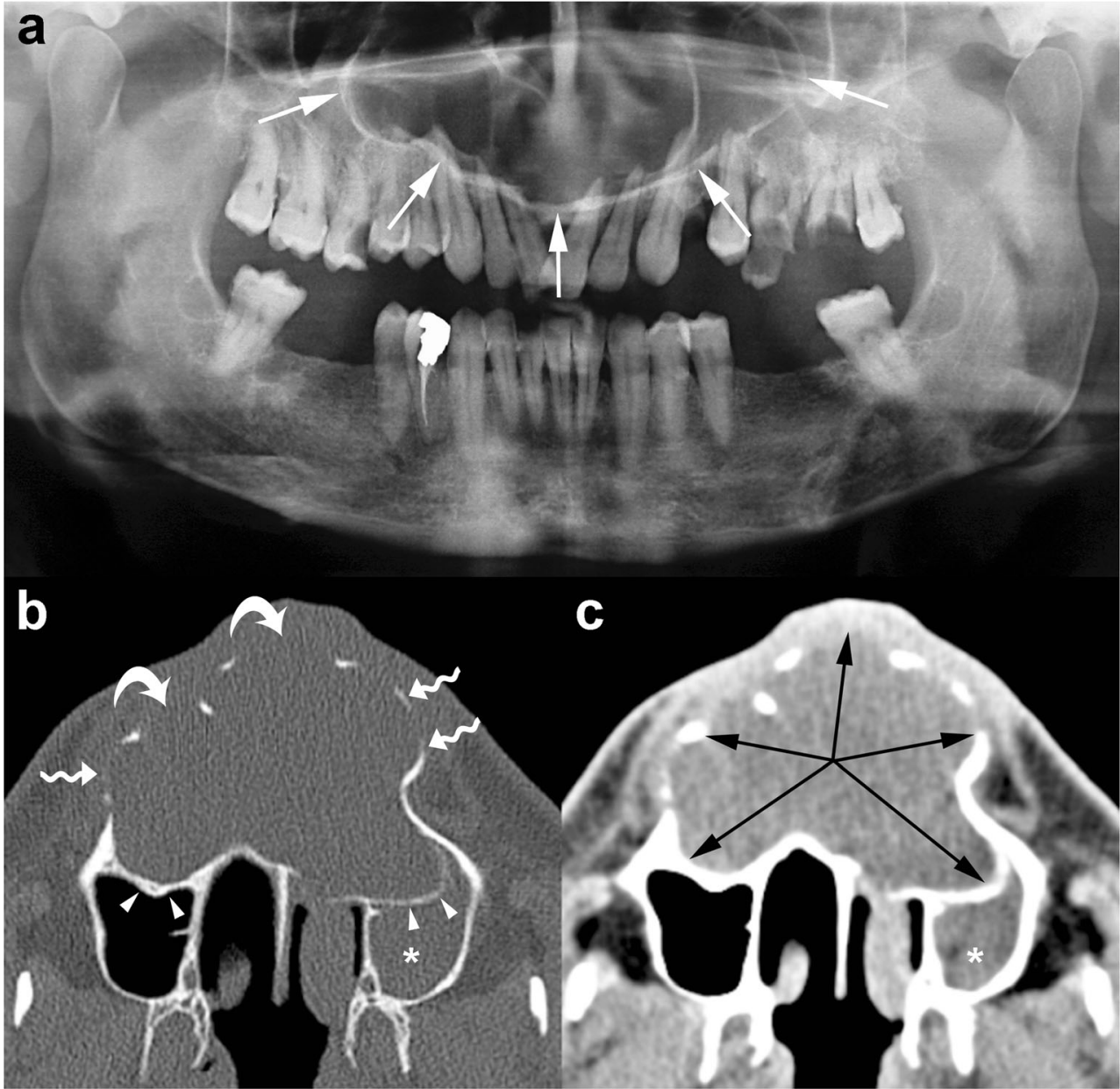

multilocular osteolytic lesions and in the preoperative assessment (Fig. 5).

In the mandible, the OKCs have a tendency to grow predominantly mesiodistally along the length of the bone, causing minimal expansion of the buccal and lingual cortical plates (Fig. 6) [33]. However, in some cases, the OKC may expand and erode the cortices (Figs. 7 and 8).

In contrast, large $\mathrm{OKCs}$ in the maxilla more frequently present a hydraulic expansion of the alveolar bone with remodelling, thinning, scalloping and perforation of the cortices (Fig. 5) [32]. In addition, when OKCs originate from the alveolar bone subjacent to the maxillary sinus, its floor is lifted and lumen is reduced (Fig. 9).

The difference between the growth pattern of mandibular and maxillary OKCs may be partly due to the higher cortical thickness of the mandible compared to that of the maxilla [15]. On CT images, OKCs typically manifest as osteolytic lesions that exhibit a unilocular (Figs. 9 and 10) or a predominantly unilocular morphology with few and incomplete septa (Figs. 7 and 8). The multilocular presentation with adjacent satellite cysts (daughter cysts) is possible, particularly in large lesions (Fig. 11). In these cases, loculations are usually large and few (soap-bubble appearance).
OKCs may be associate with an impact tooth (Fig. 6); this finding, similar to dentigerous cyst, is more common in younger patients $[14,15]$.

Internal high-density areas are frequently found and reflect the presence of keratinised material within the OKC (Fig. 12) [14]. This peculiar internal feature is detectable mainly on MDCT scan due to its better soft tissue contrast discrimination compared to CBCT scan (Fig. 12). Although rare, calcifications may occur within $\mathrm{OKCs}$; this finding is mostly observed in histological examinations (Fig. 13). Finally, at MDCT, the OKCs typically do not show enhancement after contrast administration [32].

\section{Magnetic resonance imaging}

In the evaluation of cystic lesions of the jaws, MRI is mainly performed as a complementary technique to $\mathrm{CT}$ (CBCT or MDCT), and it may be useful in selected cases to provide a better demonstration of the internal features and soft tissue involvement (Figs. 14 and 15).

OKCs typically show various signal intensity on MRI images, which reflect the materials contained inside the lesions. They are represented by a large amount of keratin sometimes 
Fig. 6 Mandibular OKC. Panoramic (a) and cross-sectional (b) cone beam computed tomography (CBCT) images display an osteolytic odontogenic lesion in the posterior left mandible and ramus, with a growth predominantly along the length of the bone (doubleheaded arrow) and minimal expansion of the buccal and lingual cortices (curved arrows). Note mesial displacement of the impacted third molar (38) and inferior displacement of the mandibular canal (arrowheads and dots). Small and incomplete internal septum (small black arrows) due to the endosteal scalloping of the cortical plate are also shown. Wavy arrow, mandibular foramen

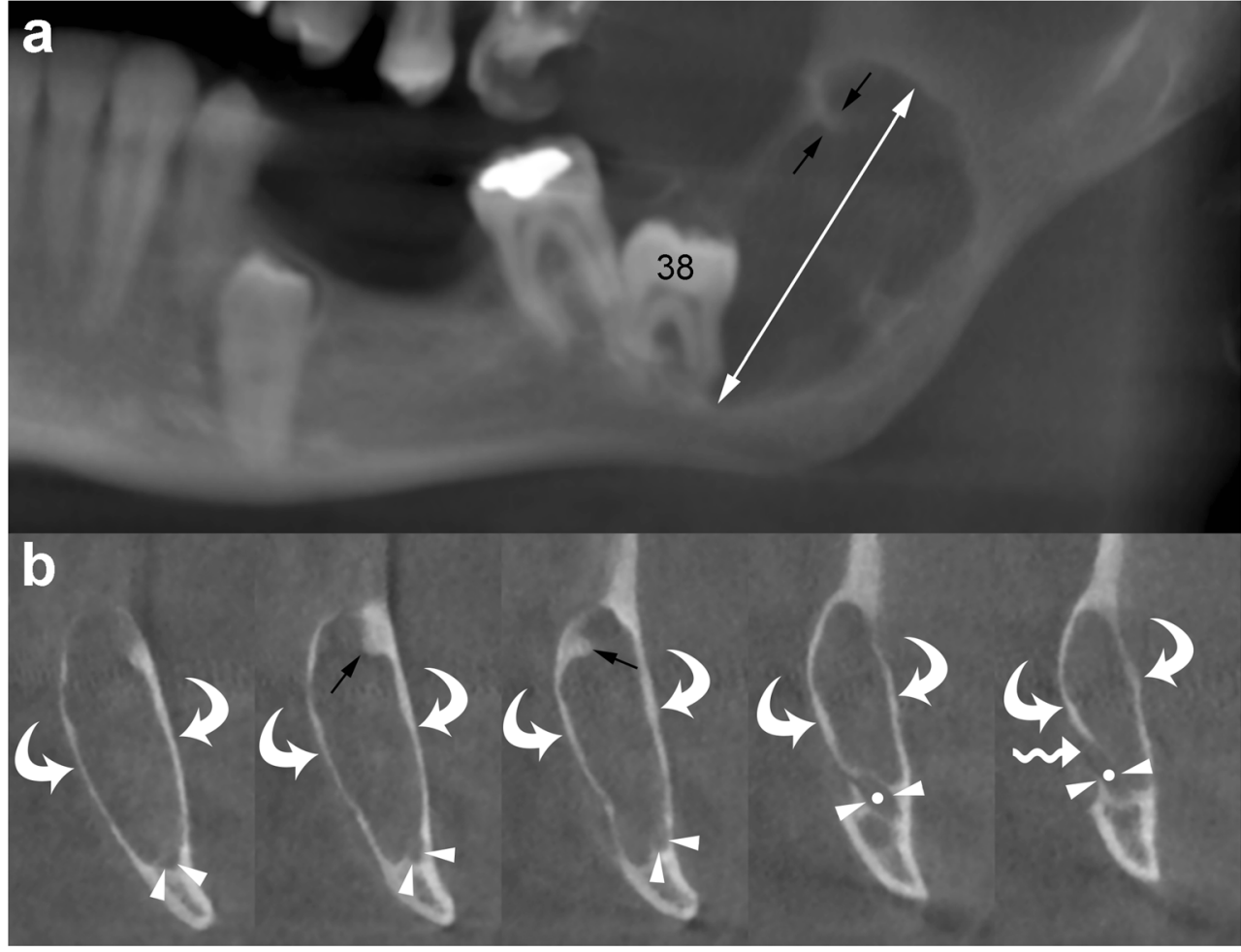

associated with hyaline bodies in the presence of inflammation [34].

Various authors reported that most of the OKCs present intermediate or high signal intensity on T1-weighted sequences and heterogeneous signal intensity (from low to high) on T2-weighted sequences (Fig. 15) [20, 32, 34, 35]. Some studies have outlined that these MRI signal features are useful in discriminating between $\mathrm{OKCs}$ and ameloblastomas [34-37]. In a retrospective study including 19 ameloblastomas and 14 OKCs, Fujita et al. [37] compared signal intensity uniformity values of the cystic components of the two types of odontogenic lesions. In agreement with other authors, they observed that the cystic components of ameloblastomas and $\mathrm{OKCs}$ displayed significantly different uniformity values on
Fig. 7 Panoramic CBCT image with 20-mm slice thickness (a) shows a mandibular OKC with a septum (opposing arrows) which seems to divide the lesion into two large loculations. Note the displacement of adjacent teeth. Panoramic (b) and axial (c) CBCT images reconstructed as 0.5 - and 0.2 -mm-thick sections demonstrate that the septum is incomplete (arrows). Perforation of the buccal cortex in the anterior portion of the lesion is also shown (curved arrows)

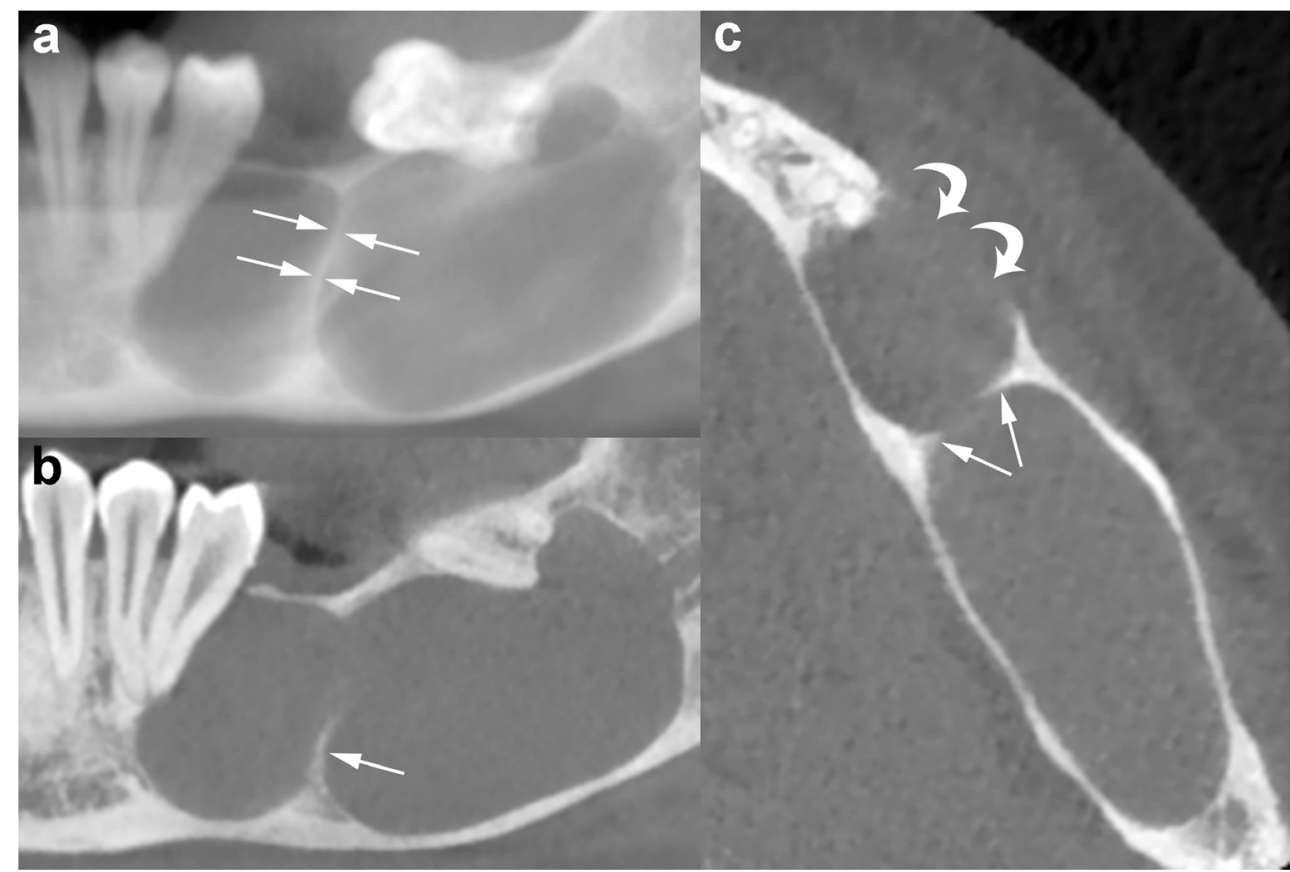


Fig. 8 Panoramic (a) and crosssectional (b) CBCT images show an OKC with well-defined and lobulated margins located in the interforaminal region of the mandible (asterisk). The lesion grows mesially by crossing the midline (white arrows). Note root resorption (arrowheads) and perforation of the cortices (curved arrows). Scalloping of the endosteal surface of the cortical plates (small black arrows) and small internal septum (wavy arrow) are also seen. Large black arrow, left mental foramen; 33, left canine; 34 , left first premolar; 35 , left second premolar; 36 , left first molar

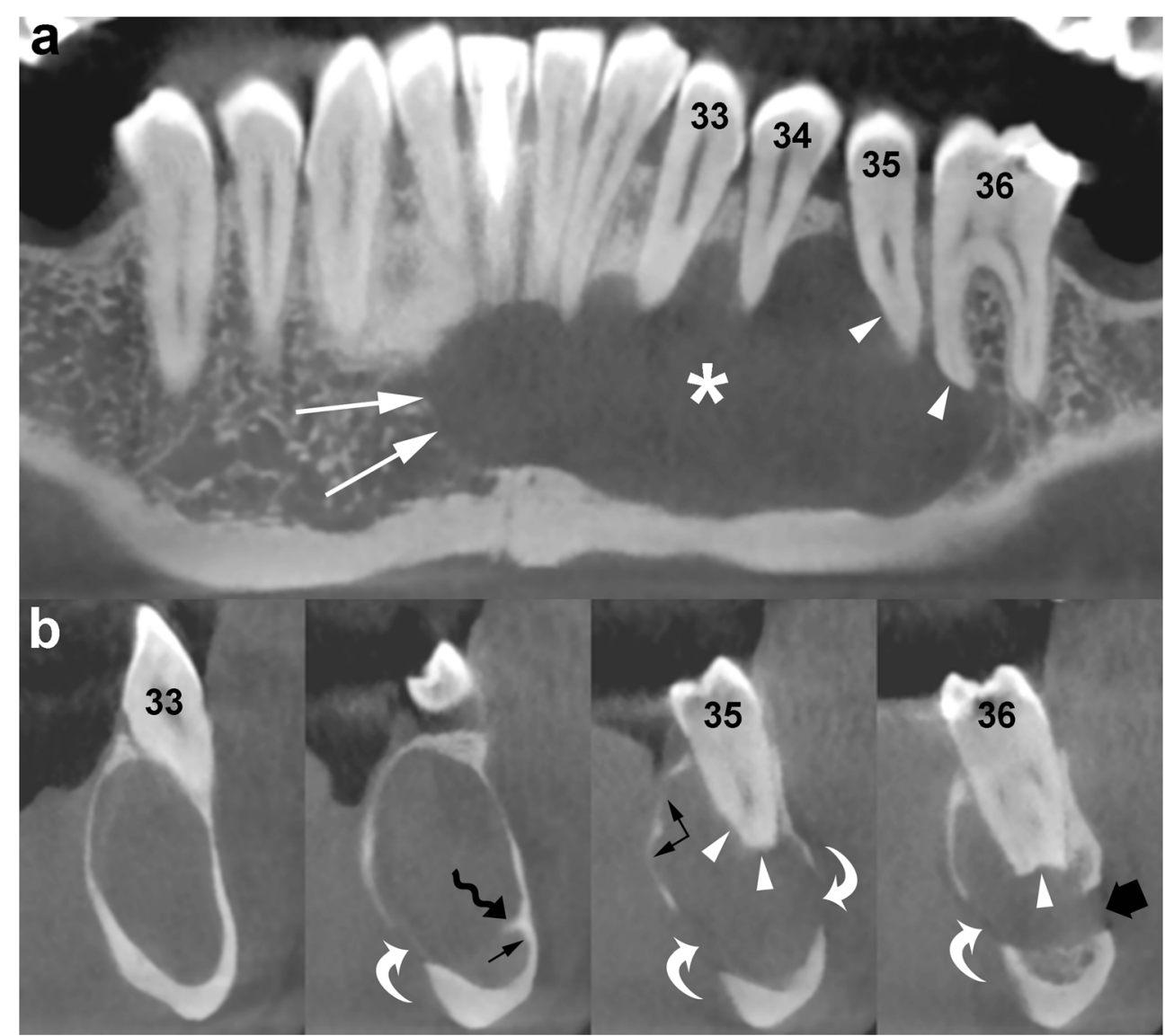

all sequences. In particular, both unicystic and multicystic ameloblastomas show a more homogeneous signal intensity that is low on the T1-weighted images and high on the T2weighted images $[35,36]$. Moreover, cystic ameloblastomas typically have a thick and irregular enhancing wall, with or without papillary projections or intralesional nodules [36]. On the other hand, OKCs tend to be associated with thin and regular rim-enhancement on T1-weighted images (Fig. 14) $[10,36]$.
MRI with diffusion-weighted imaging (DWI) and calculation of apparent diffusion coefficient (ADC) is sensitive to physiological parameters such as tissue cellularity, nucleusto-cytoplasm ratio and integrity of cell membranes, thus providing information about the microstructure of living tissues [38]. DWI may be useful as an adjunct tool for differentiation between OKCs and other odontogenic tumours, which may have overlapping imaging findings on conventional MRI sequences $[39,40]$.

Fig. 9 Panoramic CBCT images of a maxillary OKC (asterisks) originating from the molar region distally to the second molar tooth. The OKC causes significant sinus floor elevation (arrowheads). Curved arrows, posterior wall of the maxillary sinus; arrows, lateral pterygoid lamina

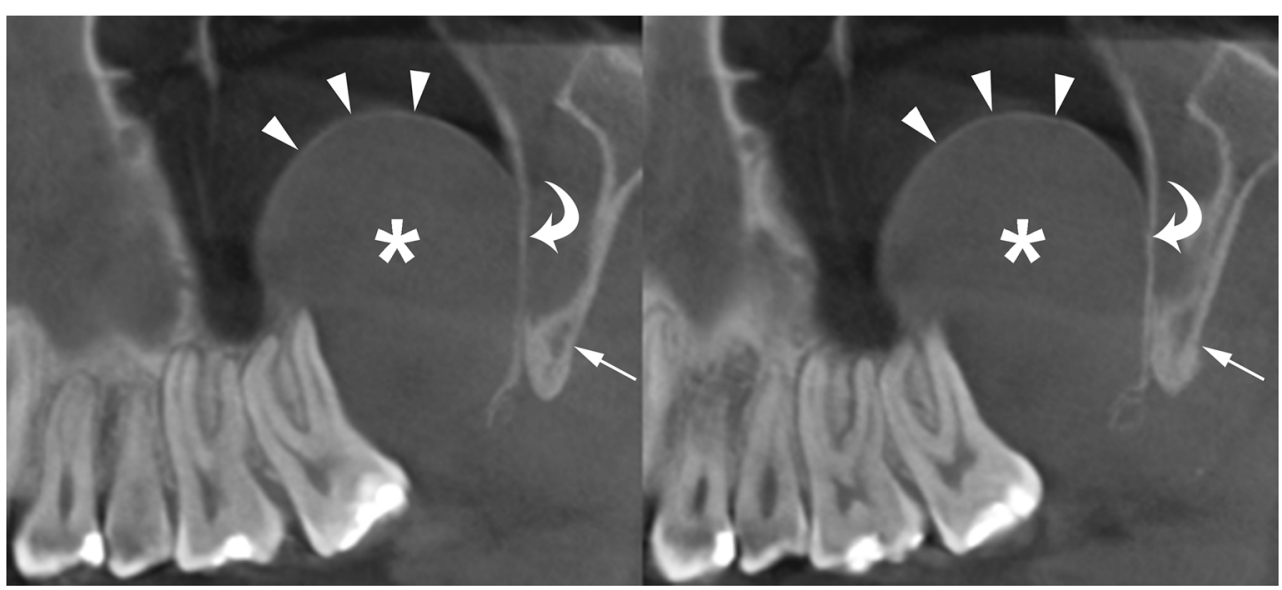




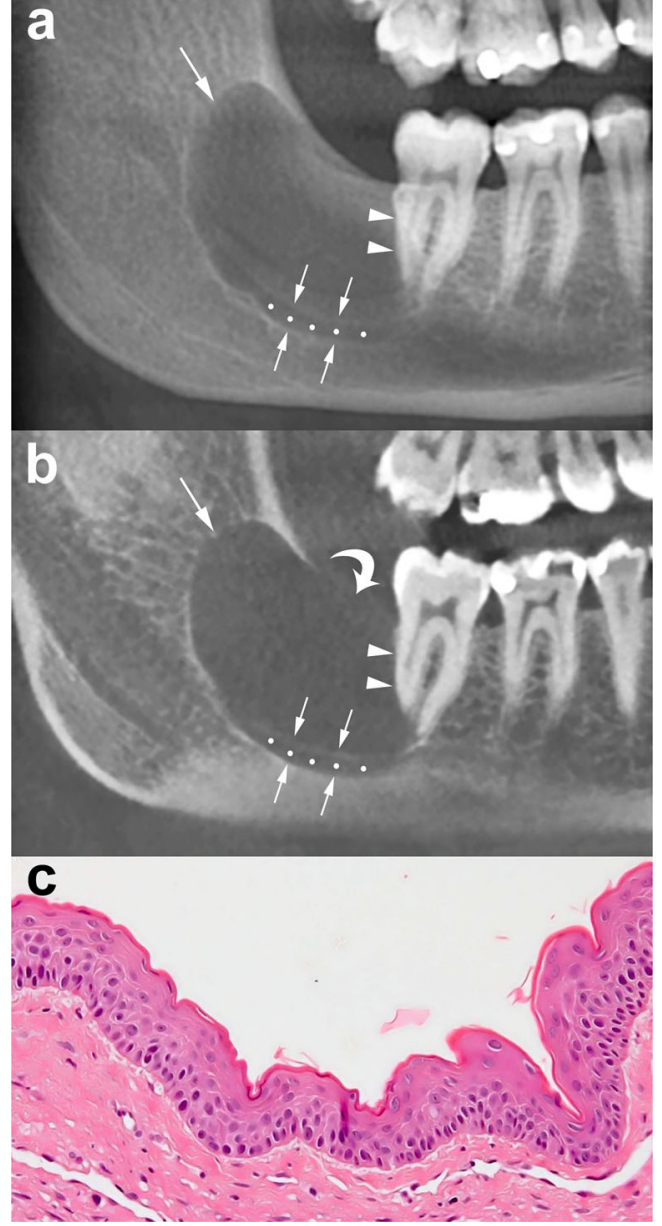

Fig. 10 Panoramic CBCT images with 20-mm (a) and 0.5-mm (b) slice thickness of an OKC show a unilocular lesion with well-defined and corticated margins located in the posterior sextant and ramus of the right mandible (arrows), near the distal root of the second molar (arrowheads). Note the interruption of the superior border of the retromolar region (curved arrow) and inferior displacement of the mandibular canal (opposing arrows and dots). c Histological image shows the typical parakeratinised stratified squamous epithelial lining with corrugated surfaces $(\mathrm{H}-\mathrm{E} 10 \times)$

In particular, as first demonstrated by Sumi et al. [39], the $\mathrm{ADC}$ value of OKCs is usually significantly lower than that of cystic/predominantly cystic ameloblastomas (Fig. 15). In a study by Srinivasan et al., the mean ADC value of OKCs was $1.019 \pm 0.07 \times 10^{-3} \mathrm{~mm}^{2} \mathrm{~s}^{-1}$ and the optimum cut-off for the differentiation with predominantly cystic ameloblastomas was $2.013 \times 10^{-3} \mathrm{~mm}^{2} \mathrm{~s}^{-1}$ [40]. These findings reflect the higher viscosity of the content of OKCs determined by the presence of floating desquamated keratin, while the cystic spaces of ameloblastomas usually contain slightly proteinaceous fluids, sometimes with colloidal materials [39]. On the other hand, benign odontogenic cysts may present a wide range of ADC values due to the varying degrees of inflammatory cells infiltration [41].

Sakamoto et al., in a retrospective study including 35 odontogenic cystic lesions, showed that diffusion kurtosis imaging (DKI) could represent a quantitative evaluation tool for better differentiating OKCs from other cystic lesions [41]. Indeed, DKI provides deeper information about tissue's structural complexity and the combination of its parameters seems to have the potential to distinguish between simple fluid viscosity and the degree of restricted diffusion caused by floating substances and, as a consequence, to increase the diagnostic accuracy for differentiating between OKCs and odontogenic cysts, compared with ADC [41].

\section{Image interpretation keys and differential diagnosis}

Radiological imaging, mainly CT (CBCT or MDCT) and, in selected cases, MRI, plays an important role in the diagnosis of OKCs. However, OKCs, in particular smaller lesions, may exhibit imaging features almost indistinguishable to other osteolytic jaw lesions. Hence, in order to obtain a definitive diagnosis, a histopathological examination is required [14]. From this point of view, radiological imaging is considered to be more useful in evaluating the extent and the effects on adjacent structures, rather than in characterising a lesion.

It is reported that, in some OKCs, the combination of clinical and radiological findings allows narrowing the differential diagnosis and, in some cases, making the correct diagnosis [18].

The imaging findings which are more effective for making a provisional diagnosis of $\mathrm{OKC}$ are:

- Well-defined unilocular osteolytic lesion in the posterior region of jaws (Fig. 10)

- Large osteolytic mandibular lesion with few septa and minimal buccolingual expansion (Fig. 6)

However, when an OKC is associated with an impacted tooth, it may simulate a dentigerous cyst. Similarly, when an $\mathrm{OKC}$ is multilocular and located in the posterior sextant or the ramus of the mandible, it may mimic an ameloblastoma. Finally, when an OKC has a periapical position or involves an edentulous area, it may be mistaken for a radicular cyst. As a result, dentigerous cyst, ameloblastoma and radicular cyst are considered the most common odontogenic lesions in the differential diagnosis of an $\mathrm{OKC}$ [32].

The imaging features which are more effective for suggesting a diagnosis of dentigerous cyst rather than of OKC are $[14,32]$ :

- Unilocular osteolytic lesion around the crown of impacted tooth

- No septa or loculation within the cyst

- More buccolingual expansion in mandible

- More homogeneous and high T2-weighted signal on MRI 
Fig. 11 Panoramic CBCT image with 20-mm slice thickness (a) shows a multilocular OKC. On this reconstruction, septa seem to divide the lesion into multiple loculations. Cross-sectional CBCT images reconstructed as 0.5-mm-thick sections (b) demonstrate that some of these septa are complete (arrowheads) and some are incomplete (wavy arrows). Note that certain small loculations shown by the asterisk, white and black stars) actually correspond to a single large loculation with scalloped borders. Compression and lingual displacement of the mandibular canal, deep to the root of the third molar (48), is also shown (opposing arrows). Curved arrow, mandibular foramen arrows, mandibular canal panoramic CBCT image (black

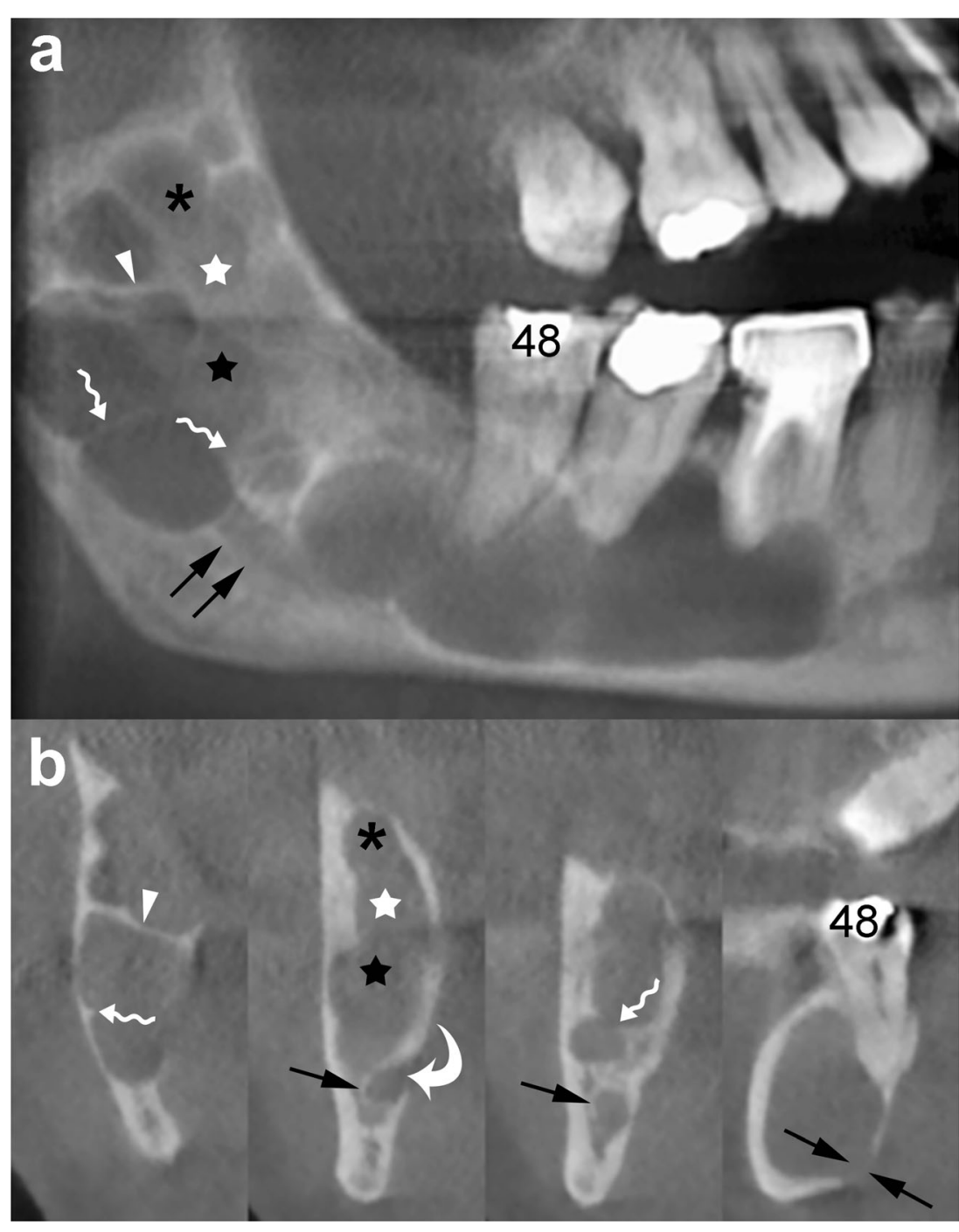

Fig. 12 Axial MDCT image with bone window (a) shows an OKC in the posterior region of the right mandible (asterisk). Axial MDCT image with soft tissue window (b) clearly demonstrates a highdensity area within the mandibular lesion (ellipse ROI) with a mean attenuation value of $80 \mathrm{HU}$

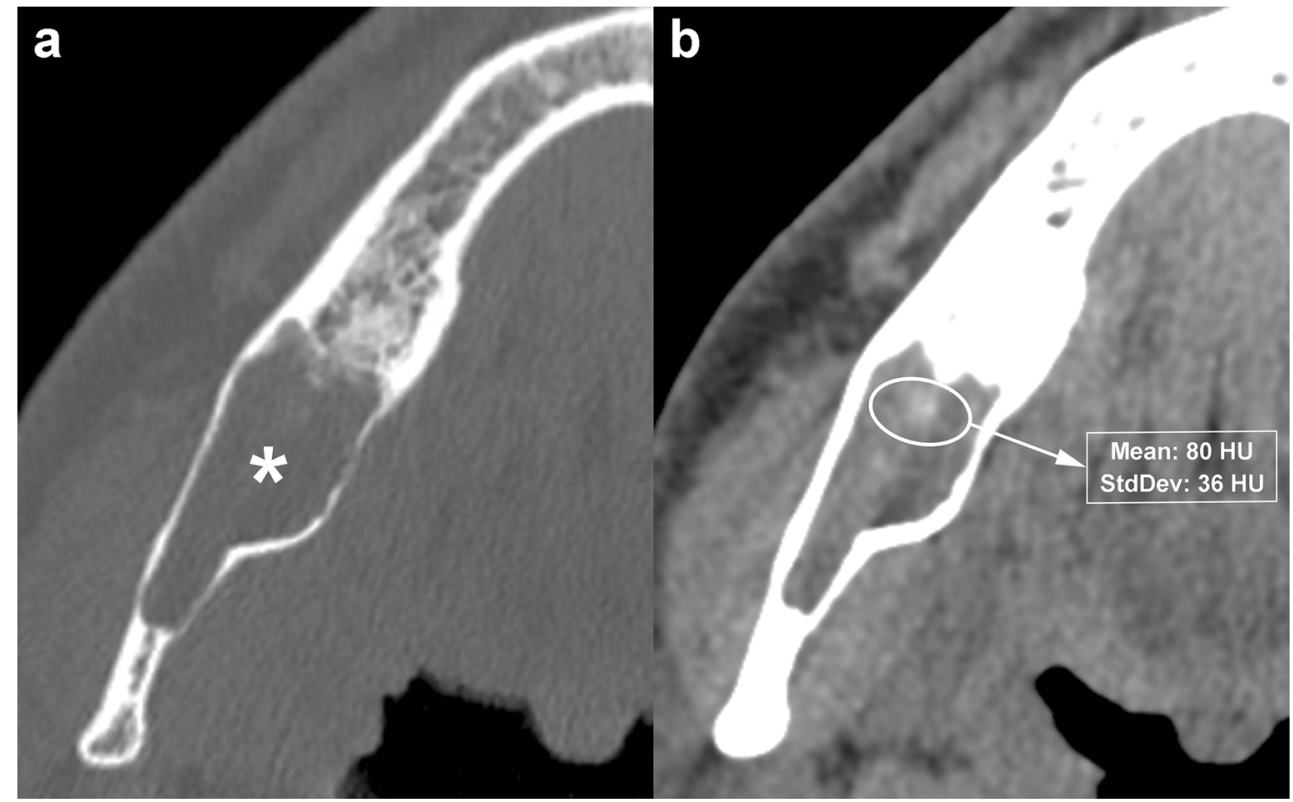


Fig. 13 Panoramic (a) and axial (b) MDCT images show an osteolytic lesion located in the interforaminal region of the mandible. The lesion,

histologically proven to represent an $\mathrm{OKC}$, causes expansion and thinning of the buccal cortex (arrowheads). MDCT images demonstrate numerous punctate high-density foci (calcification) within the lesion (arrows). One of these high-density foci shows extension into adjacent soft tissue (curved arrow). Dots, mesial portion of the mandibular canal. c Histological images show the characteristic epithelial lining and calcifications (large black arrows) within the underlying connective tissue (H-E 10×)
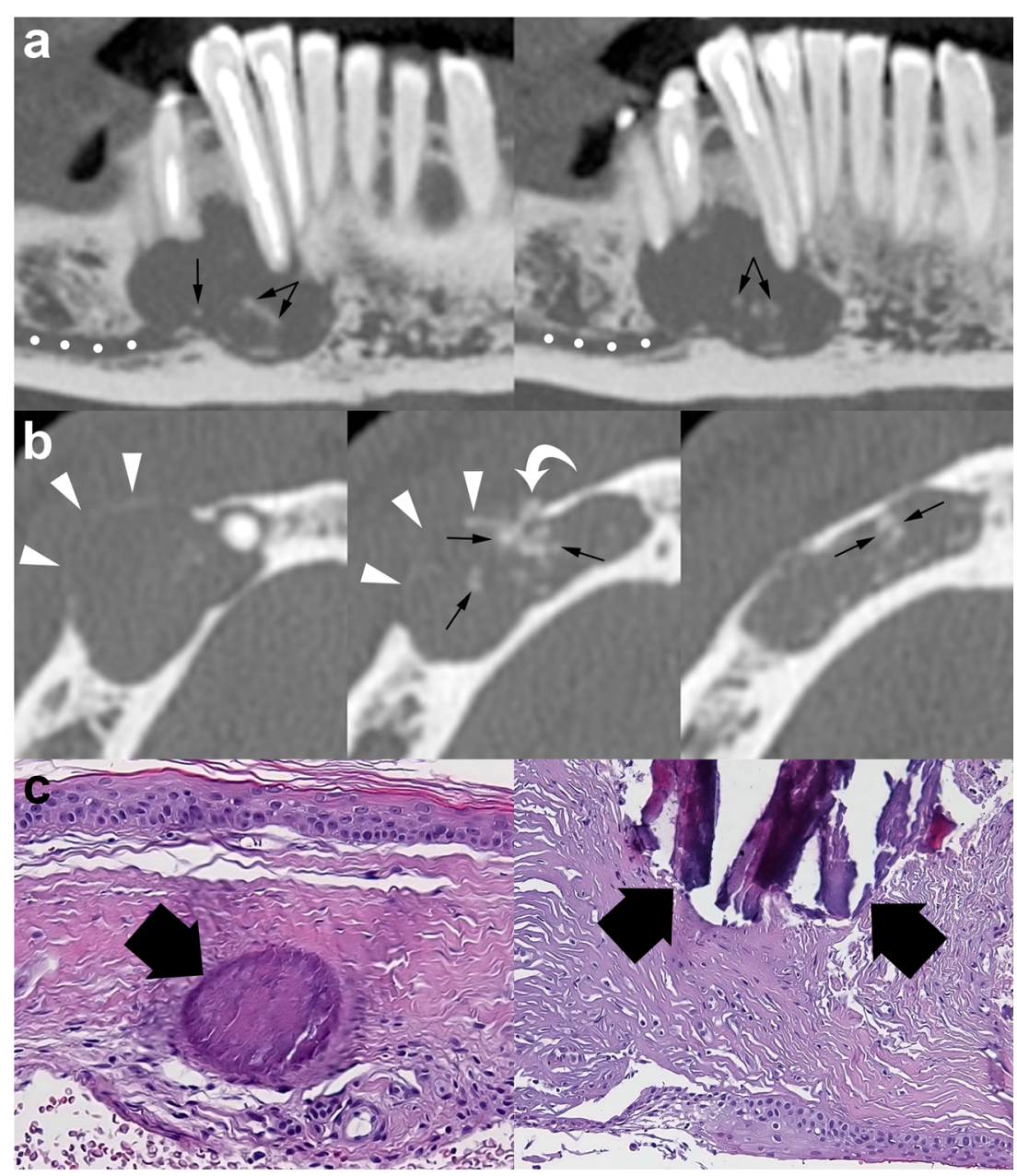

Fig. 14 Unilocular OKC in the left maxillary tuberosity. a Axial MDCT image with bone window demonstrates remodelling and thinning of the adjacent cortices (arrows). b Note thin rim enhancement within the lesion on enhanced T1-weighted fatsaturated sequence (arrowheads)
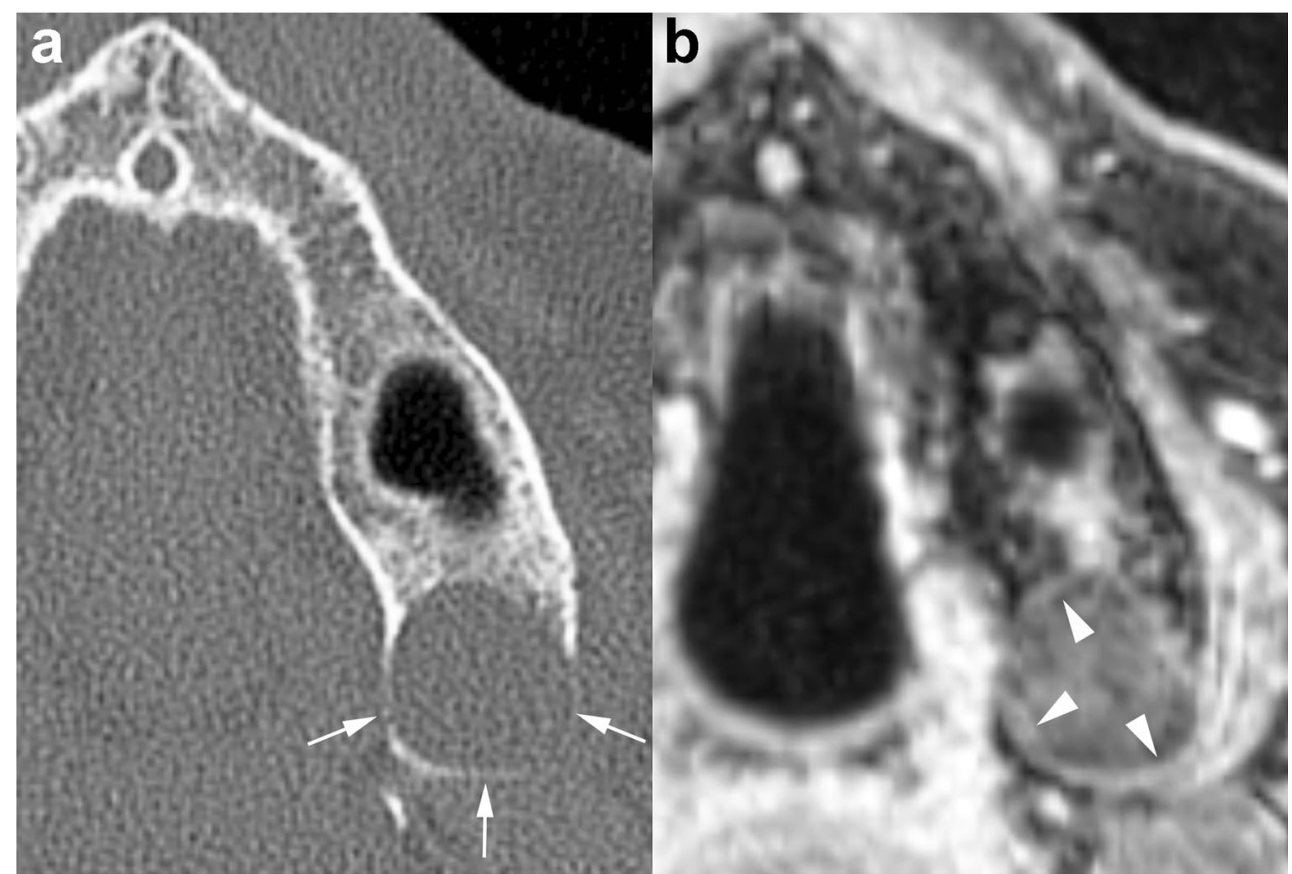
Fig. 15 Axial magnetic resonance imaging (MRI) images demonstrate the typical signal pattern of OKC. The lesion, located in the posterior left mandible (arrows), shows intermediate-high signal intensity on T1-weighted sequence (a) and heterogenous high signal intensity on T2-weighted sequence (b). No enhancement is observed within the lesion on enhanced T1weighted fat-saturated sequence (c). Diffusion-weighted imaging demonstrates restricted diffusion with high signal on b0 (d) and b1000 (e) images and low signal intensity on apparent diffusion coefficient (ADC) map (f)

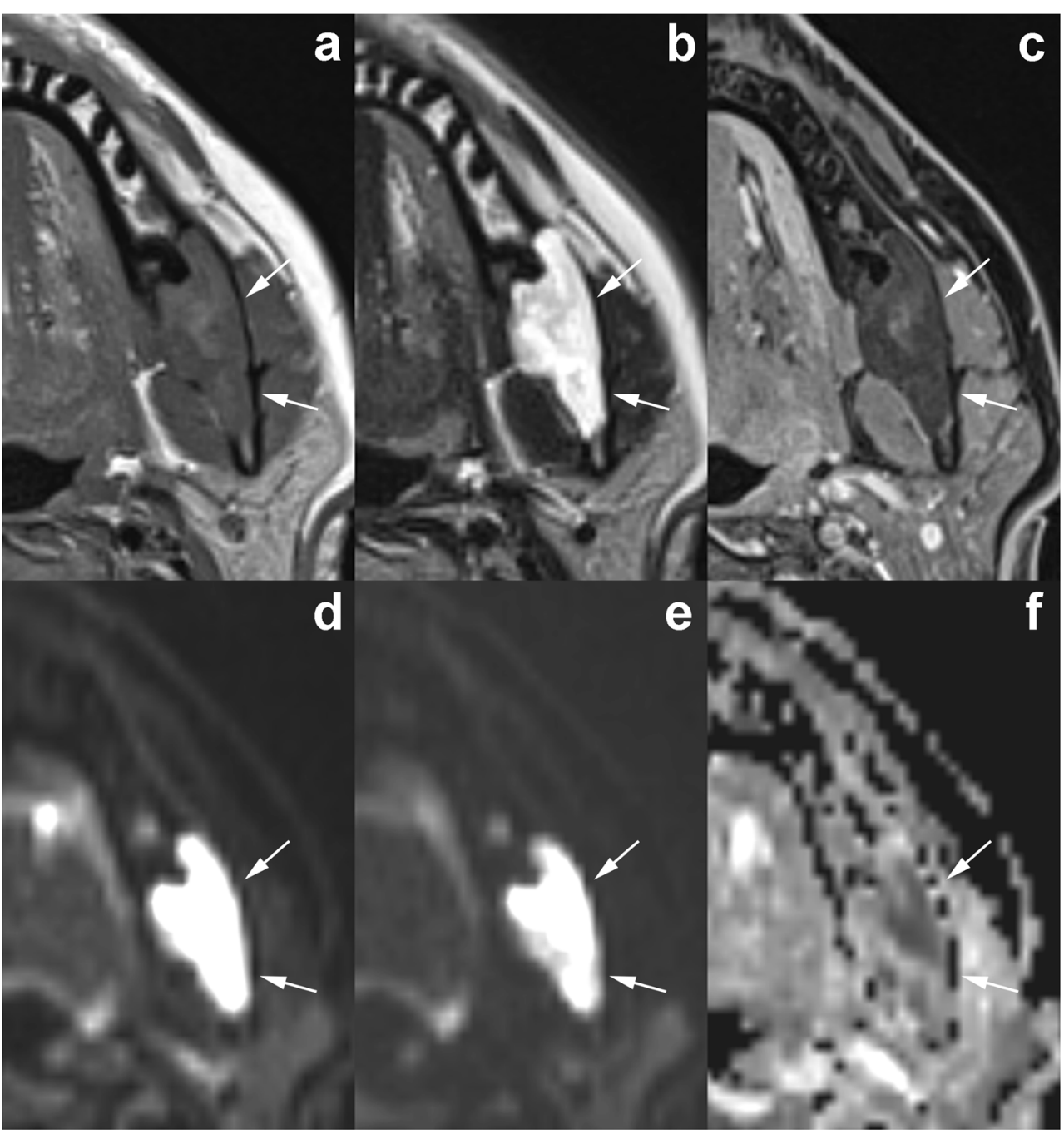

The imaging features which are more effective for suggesting a diagnosis of ameloblastoma rather than of OKC are [14, 32]:

- Multilocular osteolytic lesion with multiple internal septa

- More buccolingual expansion in mandible

- More prominent tooth displacement and root resorption

- Post-contrast enhancement of septa and mural nodule (more easily detectable on MRI rather than on MDCT)

- Mean ADC value higher than $2.013 \times 10^{-3} \mathrm{~mm}^{2} \mathrm{~s}^{-1}$ on DWI [40]

Finally, the imaging features which are more effective for suggesting a diagnosis of radicular cyst rather than of OKC are $[14,15,32,33]$ :

- Round or pear-shaped unilocular osteolytic lesion

- Epicentre at the apex of a non-vital tooth

- Iron-like density within the cyst (indicator of endodontic overfilling)
The typical features of OKCs, dentigerous cysts, radicular cysts and ameloblastomas are summarised in Table 1.

\section{Syndromic and non-syndromic multiple OKCs}

The presence of multiple OKCs is considered one of the major criteria for the diagnosis of NBCCS, and their occurrence may be the first sign of the disease [42]. NBCCS, also known as Gorlin-Goltz syndrome, is an autosomal dominant multisystemic disease characterised by multiple nevoid basal cell carcinoma, multiple OKCs, palmar or plantar pits, calcifications of falx cerebri and skeletal abnormalities, such as bifid, fused or splayed ribs [43, 44].

Other features associated with NBCCS include craniofacial, neurological, sexual, ophthalmic and cardiac anomalies [45]. The literature reported that NBCCS is associated with mutations of a tumour suppressor gene, also called the PTCH gene. Mutations within the PTCH gene are also observed in some non-syndromic OKCs. Therefore, certain authors 
Table 1 Typical characteristics of odontogenic keratocysts (OKCs), dentigerous cysts, ameloblastomas and radicular cysts

\begin{tabular}{llllll}
\hline $\begin{array}{l}\text { Odontogenic } \\
\text { lesion }\end{array}$ & $\begin{array}{l}\text { Age } \\
\text { (decade) }\end{array}$ & Gender & $\begin{array}{l}\text { Predominant } \\
\text { jaw }\end{array}$ & $\begin{array}{l}\text { Predominant } \\
\text { location }\end{array}$ & $\begin{array}{l}\text { Image interpretation } \\
\text { keys }\end{array}$ \\
\hline $\begin{array}{c}\text { Odontogenic } \\
\text { keratocysts }\end{array}$ & 3rd & M $>$ F & Mandible & Posterior & $\begin{array}{c}\text { Unilocular osteolytic lesion } \\
\text { with few septa and growth } \\
\text { along the length of the bone } \\
\text { with minimal buccolingual } \\
\text { expansion }\end{array}$ \\
$\begin{array}{c}\text { Dentigerous } \\
\text { cysts }\end{array}$ & 2nd-3rd & M $>$ F & Mandible & Posterior & $\begin{array}{l}\text { Unilocular osteolytic lesion } \\
\text { around the crown of }\end{array}$ \\
impacted tooth with \\
Ameloblastomas
\end{tabular}

indicate that the abnormalities of the PTCH gene may be involved in the pathogenesis of OKCs [46].

Multiple OKCs are also observed in other syndromes, such as Noonan syndrome, Ehlers-Danlos syndrome and oralfacial-digital syndrome.

In syndromic OKCs, the cysts occur at an early age (first or second decades of life), originate more often in the posterior sextants of the maxilla (Fig. 16), have more aggressive behaviour and their recurrence rate is higher than non-syndromic OKCs [44].

In rare case, multiple OKCs can be observed without any evidence of systemic disease [47].

However, it should be noted that the occurrence of multiple OKCs should indicate, until proven otherwise, the presence of a syndrome, and a patient with multiple OKCs should be followed regularly to assess the possible appearance of any other systemic manifestations.

\section{Treatment and follow-up}

The management of OKCs aims to reduce the risk of recurrence while minimising, at the same time, the morbidity for the patient. At the present moment, there is no consensus about the best treatment modality.

Different factors take part in the choice of the more appropriate treatment, including size and location of the lesion, unilocularity or multilocularity, presence of cortical perforation or soft tissue involvement and the patient's age.

Various surgical options have been considered, including enucleation alone or associated with adjunctive measures (ostectomy, Carnoy's solution, cryotherapy), marsupialisation and decompression, marginal or segmental resection [19].

In a systematic review of the literature, Johnson et al. showed that enucleation is associated with the highest recurrence rate of about $30 \%$, followed by marsupialisation alone

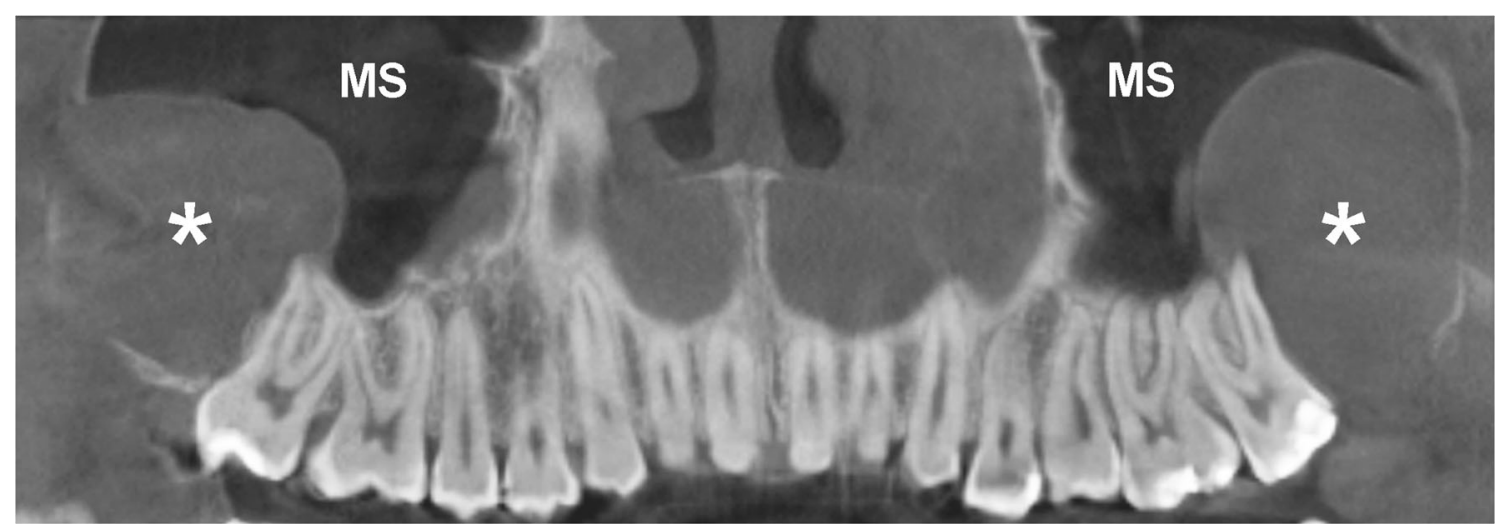

Fig. 16 Panoramic CBCT image (1 mm thick) shows two unilocular OKCs on both sides of the maxilla (asterisks) in a young male patient with nevoid basal cell carcinoma syndrome (NBCCS). Both lesions, located in the posterior sextants, extend into the maxillary sinuses $(M S)$ 
Fig. 17 Panoramic CBCT images (20 mm thick) at baseline (a) and at the first follow-up (b). At baseline (a), a large unilocular $\mathrm{OKC}$ in the posterior mandible and ramus is shown (arrowheads). At the first followup (b), performed 2 years after surgery, the CBCT image shows two recurrences in the third molar region (arrows) and ramus of the mandible (curved arrow), respectively. Wavy arrow, mandibular foramen

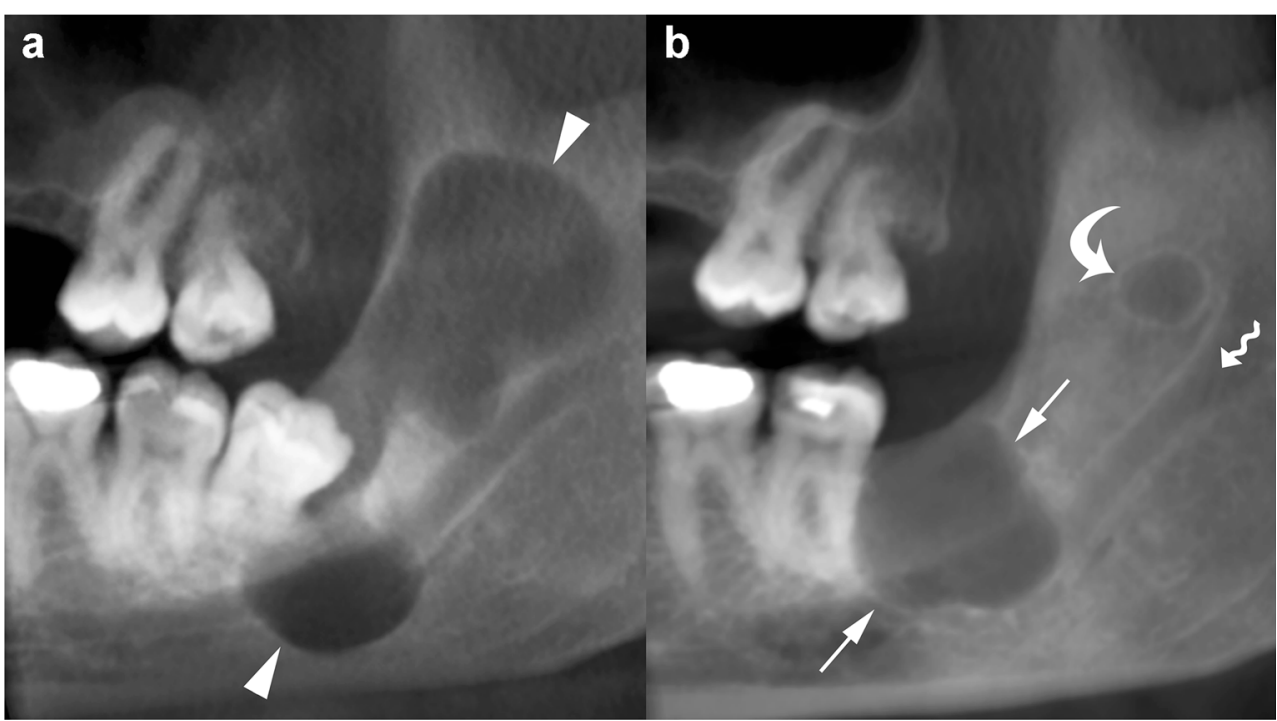

(approximately $18 \%$ recurrence rate). The association of lesion's enucleation with adjunctive technique of chemical cauterisation with Carnoy's solution, a mixture of chloroform, absolute ethanol, glacial acetic acid and ferric chloride, significantly reduced the recurrence rates to about $8 \%$ [23].

Surgical resection, both marginal and segmental, is related to the lowest recurrence rate but, because of its morbidity, is not recommended as a primary treatment modality and should be reserved for retreatment of patients suffering from multiple recurring lesions [23].

According to the literature, most recurrences of $\mathrm{OKC}$ occur within the first 5-7 years after treatment [13].
In a paper by Apajalahti et al., the mean recurrence time was relatively shorter (about 2 years). This can be explained by the systematic use of CT in the follow-up of large OKCs (Fig. 17), thus helping the radiologist to depict very small lesions that not clinically detectable [48].

For this reason, periodic radiographic monitoring of patients with surgically treated OKCs is recommended annually for the first 5 years and at least every 2 or 3 years subsequently [20]. Patients with NBCCS are particularly prone to the formation of new lesions, both in the site of previous surgery and in different sextants of the dental arches (Fig. 18). Consequently, a long-term strict radiological follow-up should be performed in these patients [23].
Fig. 18 Periodic follow-up of the same patient in Fig. 16 with NBCCS. a Axial CBCT image shows a new lesion in the third molar region of the right mandible (arrows), which was subsequently surgically treated. b A postoperative axial $\mathrm{CBCT}$ image obtained 1 year later demonstrates a very small recurrence at the site of the previous lesion (arrowheads)

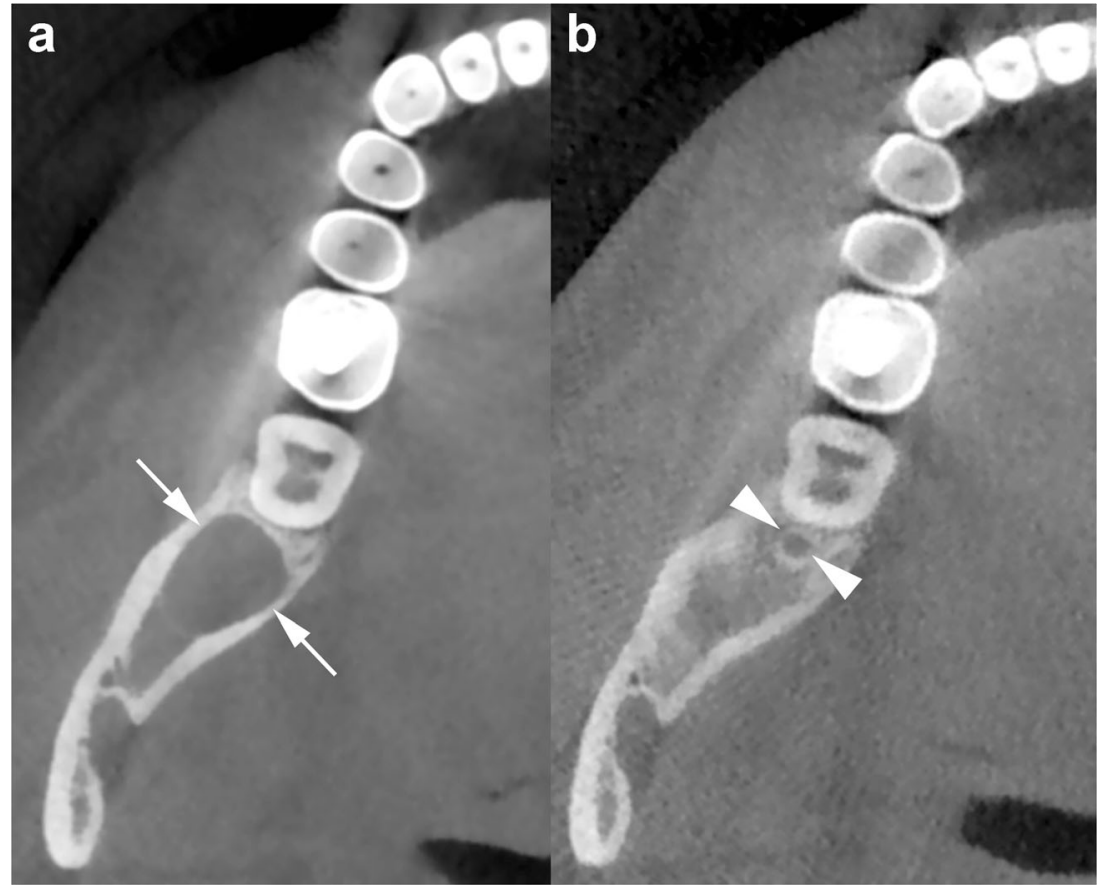




\section{Conclusions}

Odontogenic keratocysts (OKCs) are benign lesions of odontogenic origin accounting for about $10 \%$ of all odontogenic cysts and characterised by an aggressive behaviour.

Radiological imaging, mainly computed tomography (CT) and, in selected cases, magnetic resonance imaging (MRI), plays an important role in the diagnosis and management of OKCs. Although radiological imaging does not always provide a specific diagnosis, the knowledge about typical and atypical radiological features of OKCs is essential for their diagnosis and treatment planning. In particular, the combination of clinical and radiological findings is useful in evaluating the extent of the lesions and the relationships with adjacent structures.

The relatively high recurrence rate, especially after conservative surgery, make it necessary to perform a periodic radiographic monitoring of patients with surgically treated OKCs, at least for the first 5 years.

Open Access This article is distributed under the terms of the Creative Commons Attribution 4.0 International License (http:// creativecommons.org/licenses/by/4.0/), which permits unrestricted use, distribution, and reproduction in any medium, provided you give appropriate credit to the original author(s) and the source, provide a link to the Creative Commons license, and indicate if changes were made.

\section{References}

1. Philipsen HP (1956) Om keratocyster (kolesteratomer) i kaeberne. Tandlaegebladet 60:963-971

2. Antonoglou GN, Sándor GK, Koidou VP, Papageorgiou SN (2014) Non-syndromic and syndromic keratocystic odontogenic tumors: systematic review and meta-analysis of recurrences. J Craniomaxillofac Surg 42:e364-e371

3. Bilodeau EA, Collins BM (2017) Odontogenic cysts and neoplasms. Surg Pathol Clin 10:177-222

4. Aragaki T, Michi Y, Katsube K et al (2010) Comprehensive keratin profiling reveals different histopathogenesis of keratocystic odontogenic tumor and orthokeratinized odontogenic cyst. Hum Pathol 41:1718-1725

5. Barnes L, Eveson JW, Reichart P, Sidransky D (eds) (2005) Chapter 6. Odontogenic tumours. World Health Organization classification of tumors: pathology and genetics of head and neck tumours. IARC Press, Lyon

6. El-Naggar AK, Chan JKC, Grandis JR, Takata T, Slootweg PJ (2017) WHO classification of head and neck tumours, 4th edn. IARC Press, Lyon

7. Speight PM, Takata T (2017) New tumour entities in the 4th edition of the World Health Organization Classification of Head and Neck tumours: odontogenic and maxillofacial bone tumours. Virchows Arch 472:331-339. https://doi.org/10.1007/s00428-017-2182-3

8. Johnson NR, Gannon OM, Savage NW, Batstone MD (2014) Frequency of odontogenic cysts and tumors: a systematic review. J Investig Clin Dent 5:9-14
9. Chirapathomsakul D, Sastravaha P, Jansisyanont P (2006) A review of odontogenic keratocysts and the behavior of recurrences. Oral Surg Oral Med Oral Pathol Oral Radiol Endod 101:5-9

10. Avril L, Lombardi T, Ailianou A et al (2014) Radiolucent lesions of the mandible: a pattern-based approach to diagnosis. Insights Imaging 5:85-101

11. Meara JG, Li KK, Shah SS, Cunningham MJ (1996) Odontogenic keratocysts in the pediatric population. Arch Otolaryngol Head Neck Surg 122:725-728

12. Brannon RB (1976) The odontogenic keratocyst. A clinicopathologic study of 312 cases. Part I. Clinical features. Oral Surg Oral Med Oral Pathol 42:54-72

13. Woolgar JA, Rippin JW, Browne RM (1987) The odontogenic keratocyst and its occurrence in the nevoid basal cell carcinoma syndrome. Oral Surg Oral Med Oral Pathol 64:727-730

14. Harmon M, Arrigan M, Toner M, O'Keeffe SA (2015) A radiological approach to benign and malignant lesions of the mandible. Clin Radiol 70:335-350

15. MacDonald D (2016) Lesions of the jaws presenting as radiolucencies on cone-beam CT. Clin Radiol 71:972-985

16. Kaneda T, Minami M, Kurabayashi T (2003) Benign odontogenic tumors of the mandible and maxilla. Neuroimaging Clin N Am 13: 495-507

17. Ali M, Baughman RA (2003) Maxillary odontogenic keratocyst: a common and serious clinical misdiagnosis. J Am Dent Assoc 134 877-883

18. MacDonald D, Gu Y, Zhang L, Poh C (2013) Can clinical and radiological features predict recurrence in solitary keratocystic odontogenic tumors? Oral Surg Oral Med Oral Pathol Oral Radiol 115:263-271

19. Mendes RA, Carvalho JF, van der Waal I (2010) Characterization and management of the keratocystic odontogenic tumor in relation to its histopathological and biological features. Oral Oncol 46:219 225

20. Scarfe WC, Toghyani S, Azevedo B (2018) Imaging of benign odontogenic lesions. Radiol Clin North Am 56:45-62

21. Eryilmaz T, Ozmen S, Findikcioglu K, Kandal S, Aral M (2009) Odontogenic keratocyst: an unusual location and review of the literature. Ann Plast Surg 62:210-212

22. MacDonald-Jankowski DS (2011) Keratocystic odontogenic tumour: systematic review. Dentomaxillofac Radiol 40:1-23

23. Johnson NR, Batstone MD, Savage NW (2013) Management and recurrence of keratocystic odontogenic tumor: a systematic review. Oral Surg Oral Med Oral Pathol Oral Radiol 116:e271-e276

24. Shear M (2002) The aggressive nature of the odontogenic keratocyst: is it a benign cystic neoplasm? Part 2. Proliferation and genetic studies. Oral Oncol 38:323-331

25. Myoung H, Hong SP, Hong SD et al (2001) Odontogenic keratocyst: review of 256 cases for recurrence and clinicopathologic parameters. Oral Surg Oral Med Oral Pathol Oral Radiol Endod 91:328-333

26. Stoelinga PJ (2005) The treatment of odontogenic keratocysts by excision of the overlying, attached mucosa, enucleation, and treatment of the bony defect with Carnoy solution. J Oral Maxillofac Surg 63:1662-1666

27. González-Alva P, Tanaka A, Oku Y et al (2008) Keratocystic odontogenic tumor: a retrospective study of 183 cases. J Oral Sci 50:205-212

28. Kuroyanagi N, Sakuma H, Miyabe S et al (2009) Prognostic factors for keratocystic odontogenic tumor (odontogenic keratocyst): analysis of clinico-pathologic and immunohistochemical findings in cysts treated by enucleation. J Oral Pathol Med 38:386-392

29. Sánchez-Burgos R, González-Martín-Moro J, Pérez-Fernández E, Burgueño-García M (2014) Clinical, radiological and therapeutic features of keratocystic odontogenic tumours: a study over a decade. J Clin Exp Dent 6:e259-e264 
30. Neville BW, Damm DD, Brock T (1997) Odontogenic keratocysts of the midline maxillary region. J Oral Maxillofac Surg 55:340-344

31. Hodez C, Griffaton-Taillandier C, Bensimon I (2011) Cone-beam imaging: applications in ENT. Eur Ann Otorhinolaryngol Head Neck Dis 128:65-78

32. Koenig LJ, Tamimi DF, Petrikowski CG, Perschbacher SE (2017) Diagnostic imaging: oral and maxillofacial, 2nd edn. Elsevier

33. Mosier KM (2015) Lesions of the jaw. Semin Ultrasound CT MR $36: 444-450$

34. Hisatomi M, Asaumi J, Konouchi H, Shigehara H, Yanagi Y, Kishi K (2003) MR imaging of epithelial cysts of the oral and maxillofacial region. Eur J Radiol 48:178-182

35. Minami M, Kaneda T, Ozawa K et al (1996) Cystic lesions of the maxillomandibular region: MR imaging distinction of odontogenic keratocysts and ameloblastomas from other cysts. AJR Am J Roentgenol 166:943-949

36. Konouchi H, Asaumi J, Yanagi Y et al (2006) Usefulness of contrast enhanced-MRI in the diagnosis of unicystic ameloblastoma. Oral Oncol 42:481-486

37. Fujita M, Matsuzaki H, Yanagi Y et al (2013) Diagnostic value of MRI for odontogenic tumours. Dentomaxillofac Radiol 42: 20120265

38. Bammer R (2003) Basic principles of diffusion-weighted imaging. Eur J Radiol 45:169-184

39. Sumi M, Ichikawa Y, Katayama I, Tashiro S, Nakamura T (2008) Diffusion-weighted MR imaging of ameloblastomas and keratocystic odontogenic tumors: differentiation by apparent diffusion coefficients of cystic lesions. AJNR Am J Neuroradiol 29: 1897-1901

40. Srinivasan K, Seith Bhalla A, Sharma R, Kumar A, Roychoudhury A, Bhutia O (2012) Diffusion-weighted imaging in the evaluation of odontogenic cysts and tumours. Br J Radiol 85:e864-e870

41. Sakamoto J, Kuribayashi A, Kotaki S, Fujikura M, Nakamura S, Kurabayashi T (2016) Application of diffusion kurtosis imaging to odontogenic lesions: analysis of the cystic component. J Magn Reson Imaging 44:1565-1571

42. Gupta SR, Jaetli V, Mohanty S, Sharma R, Gupta A (2012) Nevoid basal cell carcinoma syndrome in Indian patients: a clinical and radiological study of 6 cases and review of literature. Oral Surg Oral Med Oral Pathol Oral Radiol 113:99-110

43. Veenstra-Knol HE, Scheewe JH, van der Vlist GJ, van Doorn ME, Ausems MG (2005) Early recognition of basal cell naevus syndrome. Eur J Pediatr 164:126-130

44. Arshad F (2016) Syndromic odontogenic keratocyst: a case report and review of literature. J Int Soc Prev Community Dent 6:84-88

45. Manfredi M, Vescovi P, Bonanini M, Porter S (2004) Nevoid basal cell carcinoma syndrome: a review of the literature. Int J Oral Maxillofac Surg 33:117-124

46. Barreto DC, Gomez RS, Bale AE, Boson WL, De Marco L (2000) PTCH gene mutations in odontogenic keratocysts. J Dent Res 79: $1418-1422$

47. Hammannavar R, Holikatti K, Bassappa S, Shinde N, Reddy M, Chidambaram YS (2014) Multiple, multifocal odontogenic keratocysts in non-syndrome patient: a case-report. Oral Health Dent Manag 13:189-193

48. Apajalahti S, Hagström J, Lindqvist C, Suomalainen A (2011) Computerized tomography findings and recurrence of keratocystic odontogenic tumor of the mandible and maxillofacial region in a series of 46 patients. Oral Surg Oral Med Oral Pathol Oral Radiol Endod 111:e29-e37

\section{Publisher's Note}

Springer Nature remains neutral with regard to jurisdictional claims in published maps and institutional affiliations. 